\title{
SYNTHES OF ROBUST ACTIVE SHIELDING SYSTEMS OF MAGNETIC FIELD GENERATED BY GROUP OF HIGH-VOLTAGE POWER LINES
}

\begin{abstract}
Aim. The synthesis of robust active shielding system of magnetic field, generated by group of high voltage power lines for reducing the induction of the initial magnetic field to the sanitary standards level and reducing the sensitivity of the system to variations in the plant parameters is given. Methodology. The synthesis is based on the solution of a multi-criteria stochastic game, in which the gain vector is calculated on the basis of the Maxwell equations solutions in the quasi-stationary approximation. The equilibrium state of the game is based on the stochastic multiagent optimization algorithms of the multiswarm particles. The initial parameters for the synthesis of active shielding system are the location of the high voltage power lines with respect to the protected from transmission line space, geometry and number of cables, operating currents, as well as the size of the protected space and normative value magnetic field induction, which should be achieved as a result of screening. The objective of the synthesis of the active shielding system is to determine their number, configuration, spatial arrangement, wiring diagrams and compensation cables currents, setting algorithm of the control systems as well as the resulting value of the induction magnetic field at the points of the protected space. Results. Robust active shielding system synthesis results for reduction of a magnetic field generated by group of high voltage power lines is given. The possibility of a significant reduction in the level of induction of the magnetic field source within and reducing the sensitivity of the system to variations in the plant parameters is given. Originality. For the first time carried out the synthesis of the robust active shielding systems of magnetic field generated by group of high voltage power lines within a given region of space. Practical_value. Practical recommendations on reasonable choice of the number and spatial arrangement of compensating cables of robust active shielding systems of the magnetic field generated by the group of high voltage power lines is given. References 18, figures 5.
\end{abstract}

Key words: high voltage power lines, power frequency magnetic field, robust active screening system, a multi-criteria stochastic game.

Цель. Проведен синтез робастной системы активного экранирования магнитного поля, создаваемого группой высоковольтных линий электропередачи для снижения индукции исходного магнитного поля до уровня санитарных норм и уменьшения чувствительности системы к изменениям параметров системы. Методология. Синтез основан на решении многокритериальной стохастической игры, в которой векторный выигрыш вычисляется на основании решений уравнений Максвелла в квазистационарном приближении. Равновесное состояние игры находится на основе алгоритмов стохастической мультиагентной оптимизации мультироем частиц. Исходными параметрами для синтеза системы активного экранирования являются расположение высоковольтных линий электропередачи по отночению к защищаемому пространству, геометрические размеры, количество проводов и рабочие токи линии электропередачи, а такжее размеры защищцаемого пространства и нормативное значение индукции магнитного поля, которое долюно быть достигнуто в результате экранирования. Целью синтеза системы активного экранирования является определение количества, конфигурации, пространственного расположения, схем электропитания и токов компенсационных кабелей, алгоритма работы системы управления, а также результирующего значения индукционного магнитного поля в точках защищаемого пространства. Результаты. Приводятся результаты синтеза робастной системы активного экранирования для уменьшения магнитного поля, создаваемого группой высоковольтных линий электропередачи. Показана возможность существенного снижения уровня индукции исходного магнитного поля внутри заданного пространства и снижения чувствительности системы к изменениям параметров системы. Оригинальность. Впервые проведен синтез робастной системы активного экранирования магнитного поля, создаваемого группой высоковольтных линий электропередач в данной области пространства. Практическая ценность. Приводятся практические рекомендации по обоснованному выбору количества и пространственного расположения компенсирующих обмоток робастных систем активного экранирования магнитного поля, создаваемого группой высоковольтных линий электропередач. Библ. 18, рис. 5.

Ключевые слова: высоковольтные линии электропередачи, магнитное поле промышленной частоты, робастная система активного экранирования, многокритериальная стохастическая игра.

Introduction. Methods of active contour shielding of power frequency magnetic field (MF) created by high voltage power lines (HVPL) [1-6] are the most acceptable and economically feasible for ensuring the sanitary norms of Ukraine in the magnetic field of the industrial frequency [7-8]. The method of synthesis of active shielding systems (ASS) for MF, created by air power lines, was developed in [9]. The initial data for the synthesis of the system is the parameters of the transmission lines (working currents, geometry and number of wires, location of the transmission lines relative to the protected space) and the dimensions of the protected space and the standard value of the induction of the MF, which should be achieved as a result of screening. In the process of synthesis, it is necessary to determine the parameters of the compensation coil (their number, configuration, spatial arrangement, connection diagram), compensating coil currents and the resulting induction values of the MF at the points of the protected space, as well as the algorithm of the ASS. However, this method [9] does not take into account the uncertainty of the system parameters due to the inaccurately known model of the control object, as well as changes in the parameters of the system during its operation [10].

Ukraine's electricity networks are characterized by high density, and especially near high-voltage power substations. There is usually a group of overhead HVPL, in the immediate vicinity of which can be located

(C) B.I. Kuznetsov, T.B. Nikitina, V.V. Kolomiets, I.V. Bovdui, A.V. Voloshko, E.V. Vinichenko 
residential buildings. In this case, the main uncertainty in the synthesis of this system is the variation of the currents of different power lines, which leads not only to a change in the level of magnetic field induction, but also to a change in the position of the space-time characteristics (STC) of the MF in the shielding zone.

The goal of this work is the synthesis of robust active shielding systems of power frequency magnetic field created by group of high voltage power lines, which allows to reduce the magnetic field level to sanitary norms and to reduce the sensitivity of the system to variations of plant parameters.

Problem statement considers the formulation of the problem of synthesis of the robust ASS. In the synthesis of the ASS, the mathematical model of the original MF is known inaccurately [10]. In particular, currents in current conductors that have daily, weekly, seasonal variations are approximately known. The geometric dimensions of the compensating coil, the parameters of the regulators, etc. are not accurately realized. Therefore, we introduce a vector of deviations of the system parameters from their nominal values $\delta$ used in the synthesis of the system. The problem of synthesizing a robust ASS is reduced to the determination of such a vector of spatial arrangement and geometric sizes of compensated windings, as well as parameters of the regulator $X$ and the vector of variable parameters $\delta$, at which the maximum value of the magnetic field induction at selected points $P_{j}$ of the considered space $P$ assumes a minimum value for the regulator parameter vector $X$, but the maximum value for the vector of variable parameters $\delta$ so that

$$
X^{*}=\arg \min _{X \in \boldsymbol{X}} \max _{\delta \in \Delta} \max _{j} \in \boldsymbol{P}\left(X, \delta, P_{j}\right) .
$$

This technique corresponds to the standard approach to the synthesis of robust systems for the worst-case [10], when the variations of the parameters $\delta$ lead to the greatest deterioration in the compensation of the initial MF created by HVPL. The problem (1) can be formulated in the form of the following multi-criteria game [11] with vector gain

$$
B(X, \delta)=\left[B\left(X, \delta, P_{1}\right), B\left(X, \delta, P_{2}\right) \ldots B\left(X, \delta, P_{m}\right)\right]^{T},
$$

the components of which $B\left(X, \delta, P_{i}\right)$ are the MF induction vector module in the $m$ points $P_{i}$ of the space under consideration. In this case, of course, it is necessary to take into account the constraints on the control vector and the state variables of the system, the vector of the unknown and variable parameters in the form of a vector inequality

$$
G(X, \delta) \leq G_{\max }
$$

In the multi-criteria game (2), the first player is the parameter vector of the regulator $X$ and its strategy is the minimization of the vector gain (2), and the second player is a vector $\delta$ of variable parameters characterizing the uncertainty of the plant parameters and the strategy of this player is maximization of the same vector gain [11].

Note that the components of the vector gain (2) are nonlinear functions of the required parameters vectors $X$ and $\delta$ are calculated on the basis of the solutions of the Maxwell equations in the quasistationary approximation [12-16].
Method of synthesis. Consider the algorithm for finding the equilibrium of the game problem. To find the equilibrium state of the multi-criterion game (2) from Pareto-optimal solutions taking into account the preference relations [11], we construct an algorithm for stochastic multi-agent optimization based on the set of particle swarms [17], the number of which $m$ is equal to the number of components of the vector gain (2). The motion of $i$ particle of $j$ swarm is described by the following expressions

$$
\begin{gathered}
v_{i j}(t+1)=w_{j} v_{i j}(t)+c_{1 j} r_{1 j}(t) H\left(p_{1 j}-\varepsilon_{1 j}(t)\right)\left[y_{i j}(t)-\ldots\right] \\
{\left[\ldots-x_{i j}(t)\right]+c_{2 j} r_{2 j}(t) H\left(p_{2 j}-\varepsilon_{2 j}(t)\right)\left[y_{j}^{*}(t)-x_{i j}(t)\right]} \\
u_{i j}(t+1)=w_{j} u_{i j}(t)+c_{1 j} r_{1 j}(t) H\left(p_{1 j}-\varepsilon_{1 j}(t)\right)\left[z_{i j}(t)-\ldots\right] \\
{\left[\ldots-\delta_{i j}(t)\right]+c_{2 j} r_{2 j}(t) H\left(p_{2 j}-\varepsilon_{2 j}(t)\right)\left[z_{j}^{*}(t)-\delta_{i j}(t)\right],} \\
x_{i j}(t+1)=x_{i j}(t)+v_{i j}(t+1) \\
\delta_{i j}(t+1)=\delta_{i j}(t)+u_{i j}(t+1),
\end{gathered}
$$

where $x_{i j}(t), \delta_{i j}(t)$ and $v_{i j}(t), u_{i j}(t)$ is the position and velocity of $i$ particle of $j \operatorname{swarm} ; y_{i j}(t), z_{i j}(t)$ and $y_{j}^{*}, z_{j}^{*}-$ the best local - lbest and global - gbest positions of the $i$-th particle, found respectively by only one $i$-th particle and all the particles of $j$ swarm.

Moreover, the «best» position of the $-j$ particle of $j$ swarm on a vector $x_{i j}(t)$ is understood in the sense of a minimum of the scalar gain $B\left(X, \delta, P_{j}\right)$, and by the vector $\delta_{i j}(t)$ is understood in the sense of the maximum of the same scalar gain. Positive constants $c_{1}, c_{2}$, random numbers $r_{1 j}(t), r_{2 j}(t)$, inertia coefficients $w_{j}$ and switching functions $H$ are tuning parameters of the algorithm.

Note that in connection with the fact that the vector of the solutions of the game (2) is represented in the form of strategies of two players $X$ - the vector of the parameters of the regulators and the $\delta$ - the vector of the variable parameters of the plant, where it is necessary to minimize the vector gain (2) along the regulators parameter vector $X$ and maximize the same vector gain (2) with respect to the of plant parameters variable vector $\delta$. Therefore, each $i$ particles of $j$ swarm has two components of position $x_{i j}(t), \delta_{i j}(t)$ and two components of velocity $v_{i j}(t), u_{i j}(t)$ to find the two desired components of the regulators parameters vector $X$ and the variable parameters vector $\delta$.

In conclusion, we note that the original multi-criteria game (2), (3), taking into account the algorithm for its solution (4) - (7), is a multi-criteria stochastic dynamic game, since it clearly has time and random search $[6,7]$.

Computer simulation results. Consider the result of synthesis of robust ASS of MF created by group of HVPL. This situation is typical for the outskirts of cities, where several power lines are suitable, as well as near power line substations. The layout of group of HVPL, compensating coil and screening zone of the system under consideration is shown in Fig. 1. In the immediate vicinity of the shielding zone there are two doublecircuit $110 \mathrm{kV}$ HVPL-1 and HVPL-2, a double-circuit $330 \mathrm{kV}$ HVPL-3 and a single-circuit $330 \mathrm{kV}$ HVPL-4. 


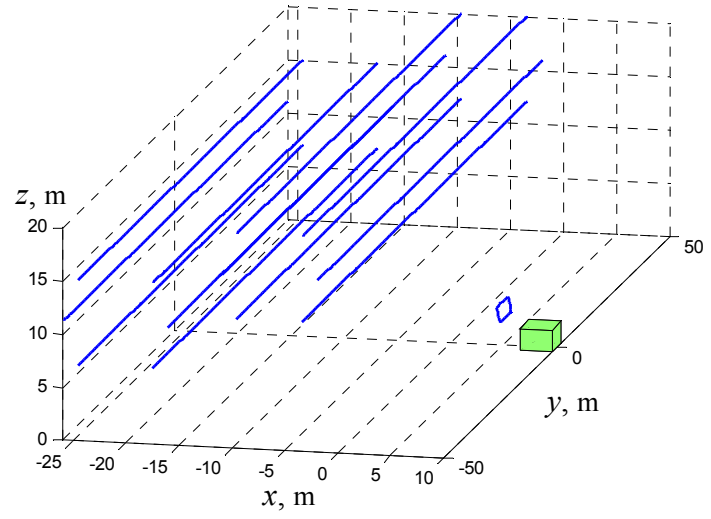

Fig. 1. Layout of group of high voltage power lines, compensating coil and screening zone

For the synthesis of ASS, in addition to the geometric dimensions of the transmission lines and the shielding zone, the values of the currents in the current conductors of the all HVPL are necessary. To this, first, experimental studies of the level of the magnetic field both in the shielding zone and near the transmission lines were carried out. Based on the obtained experimental data, the problem of current identification in current conductors of the power line is solved, under which the sum of the squares of the errors of the measured and model-them magnetic field induction values at given points is minimized.

In Fig. 2 shows the equal level lines of the initial magnetic field induction vector module.

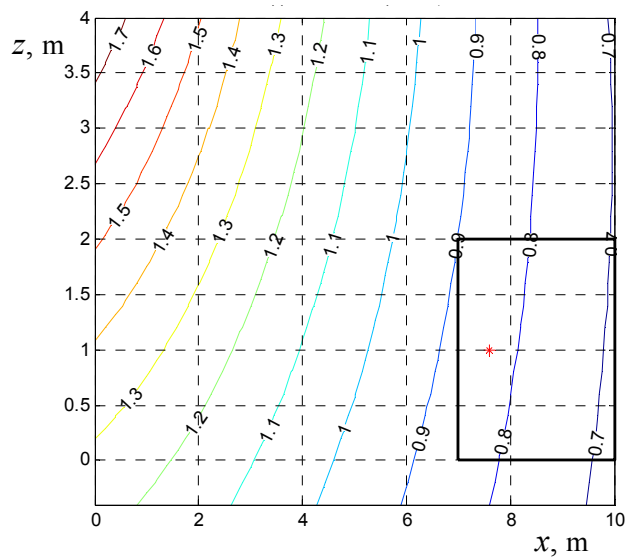

Fig. 2. Equal level lines of the initial magnetic field induction vector module

The MF initial induction generate by HVPL in the space under consideration is $0.9 \mu \mathrm{T}$, which is 1.8 times higher than the MF sanitary standards of Ukraine.

Based on the model of MF created by group of HVPL, the problem of synthesis of a robust ASS was solved. The ASS contains one compensation coil.

On the basis of experimental research, it was found that in the shielding zone, the MF generated by group of HVPL has the space-time characteristics (STC) of such MF is a strongly elongated ellipse [9] and, consequently, the initial $\mathrm{MF}$ has a negligible polarization. Active screening of such MF is possible with the use of single compensation coil. It should be noted that such systems have become most widespread in the world practice [2].
In Fig. 3 shows the equal level lines of the compensation coil magnetic field induction vector: module (a), component along $Z$ axes (b) and component along $X$ axes $(c)$ with the robust active screening system is on.
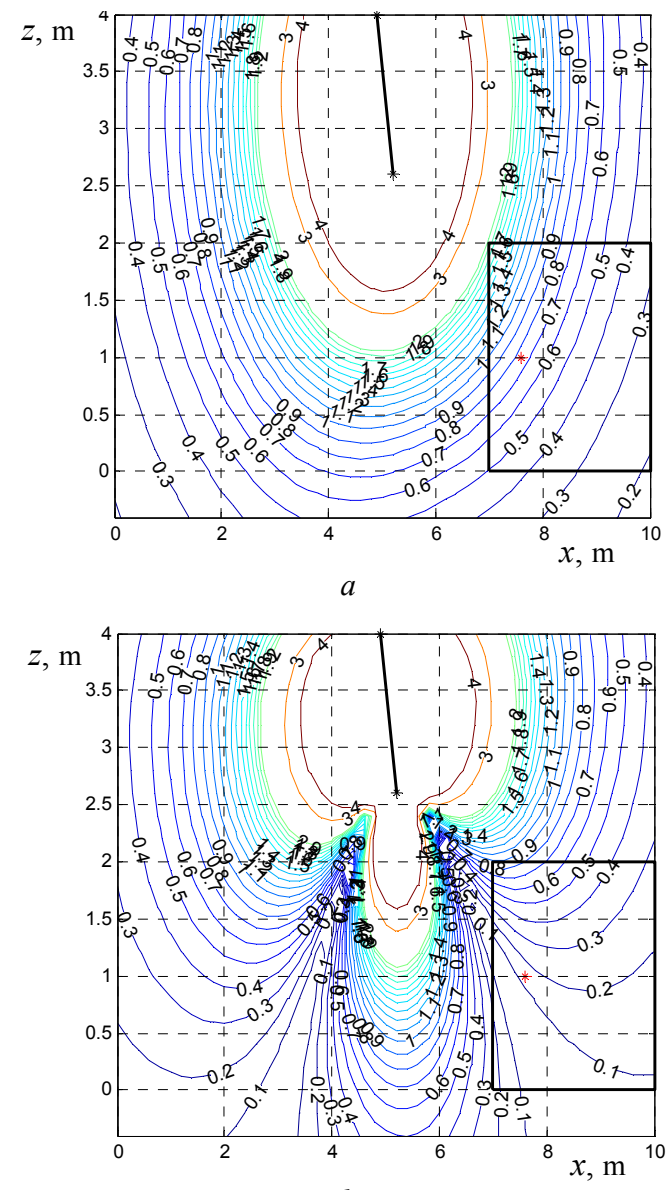

$b$

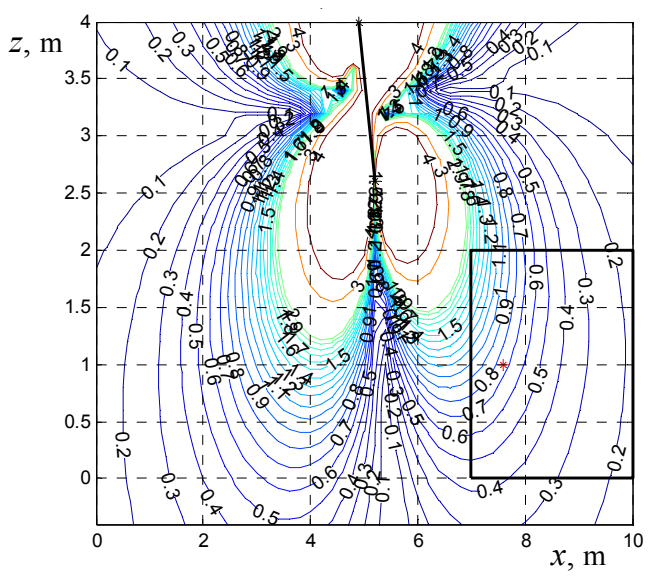

$c$

Fig. 3. Equal level lines of the compensation coil magnetic field induction vector: module $(a)$, component along $Z$ axes $(b)$ and component along $X$ axes $(c)$ with the robust active screening system is on

In Fig. 4 shows the equal level lines of the magnetic field induction vector: module $(a)$, component along $Z$ axes (b) and component along $X$ axes (c) with the robust active screening system is on. When the active shielding system is on, as can be seen from Fig. 3, the MF induction level in the residential space under consideration does not exceed $0.5 \mu \mathrm{T}$. 

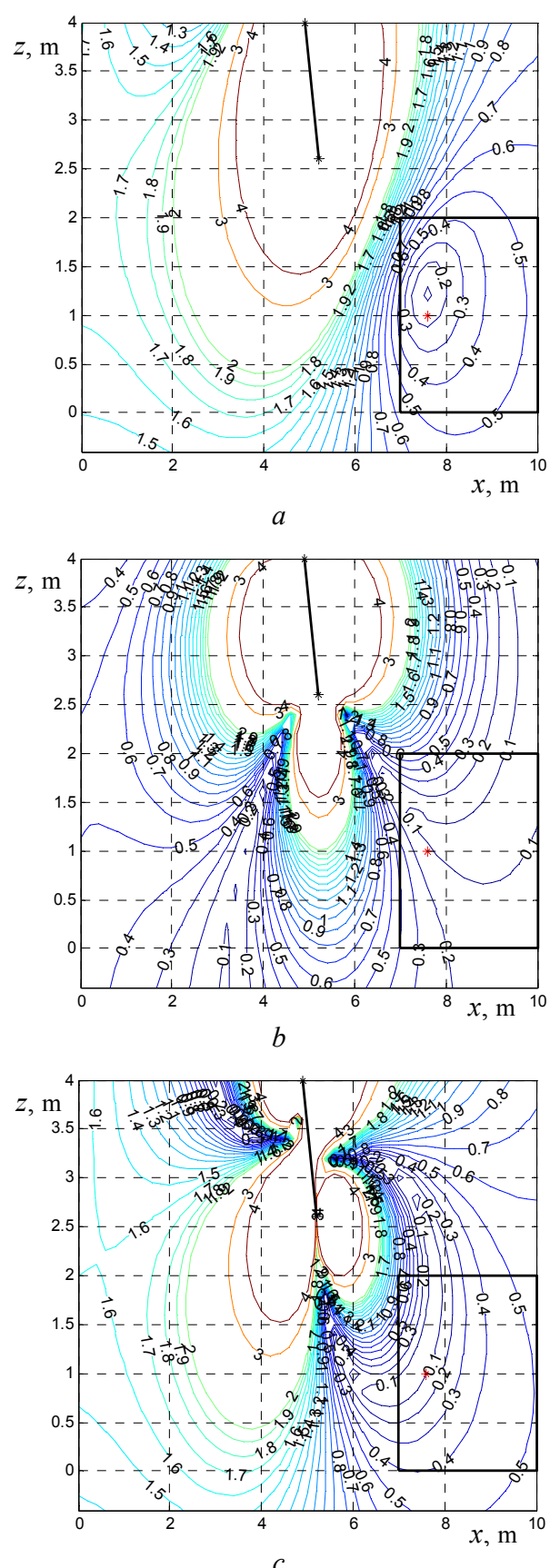

Fig. 4. Equal level lines of the magnetic field induction vector: module ( $a$ ), component along $Z$ axes $(b)$ and component along $X$

axes $(c)$ with the robust active screening system is on

In Fig. 5 shows the STC of MF, created by group of HVPL (1); compensating coil (2) and total MF with the ASS is on (3). Naturally, such a MF can be effectively compensated for using a single-loop ASS. With single coil, the big axis of the STS ellipse of the initial MF is compensated, so that the STS of the total MF with the ASS is on is an ellipse with an ellipse coefficient 0.8 .

In the robust system, the maximum value of the magnetic induction in the protected zone does not exceed $0.5 \mu \mathrm{T}$, which corresponds to the sanitary norms of Ukraine [7]. For the worst-case scenario, when vector parameters variations lead to the greatest deterioration in the compensation of the initial magnetic field by a robust system, the maximum value of the level of magnetic induction in the protected zone increases by $10 \%$ compared to the robust system at nominal values of the parameters when the vector $\delta=0$. In spite of the fact that in the initial optimal system with nominal values of the parameters, the maximum value of the level of magnetic induction in the protected zone is approximately $10 \%$ less than in robust systems and is $0.4 \mu \mathrm{T}$. However, when the vector of variable parameters is changed for the worstcase case, the maximum value of the level of magnetic induction in the initial optimal system increases to $0.6 \mu \mathrm{T}$.

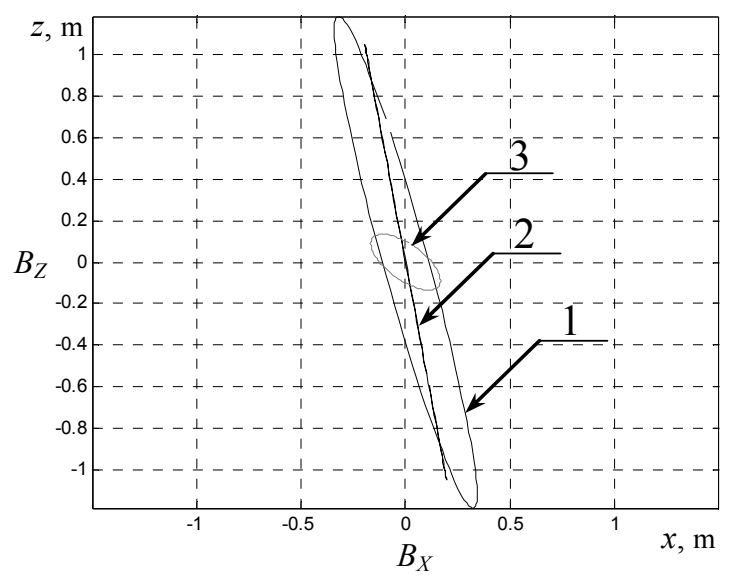

Fig. 5. Space-time characteristics of magnetic field: initial (1), compensation coil (2) and resultant magnetic field with the robust active screening system is on (3)

Note that the position of the compensating coil of the robust system, shown in Fig. 3, slightly differs from the position of the compensating coil of the optimal system [9]. Also, the parameters of the controllers of the robust and original optimal system are not significantly different, as a result of which the robustness of the synthesized system with respect to the optimal system is ensured.

Thus, the synthesized robust ASS makes it possible to reduce the sensitivity of the system to changes in the parameters of the control object in comparison with the initial ASS.

Experimental research results. Consider the field experimental research of the full scale ASS layout [18]. Compensation coil of the full scale ASS layout is a square shape, the upper branch of which is located at a height of $4 \mathrm{~m}$ from the ground, and the lower branch is located at a height of $2.6 \mathrm{~m}$ from the ground. The compensation coil contains 20 winds and is powered by amplifier type TDA7294.

The ASS contains an external MP induction controller and an internal current controller. An inductive sensor is used as an MF induction sensor, and the MP measurement is performed by EMF-828 type magnetometer of the Lutron Firm. The ASS is powered by an autonomous source. Field experimental research of a single-loop MF ASS with open and closed-loop control algorithms were carried out. The results of comparison of experimental and calculated of MP induction values in a residential zone are given. It is shown that the experimental and calculated MF induction values differ by not more than $10 \%$.

\section{Conclusions.}

1. For the first time the synthesis of robust active screening system of magnetic field, generated by group of 
high voltage power lines for reducing the induction of the initial magnetic field to the sanitary standards level and reducing the sensitivity of the system to variations in the plant parameters is given.

2 . The synthesis of a robust active screening system is based on multi-criteria stochastic game decision, the equilibrium state of which is based on multiswarm stochastic multi-agent optimization from Pareto-optimal solutions.

3. As a result of active screening system synthesis the spatial position of one compensation coil and the parameters of the regulator are determined. System reduce the level of the initial magnetic field induction throughout the considered residential area up to the Ukraine sanitary norms level and has less sensitivity to plant parameters variations in comparison with the known systems.

\section{REFERENCES}

1. Rozov V.Yu., Reutskyi S.Yu., Pelevin D.Ye., Pyliugina $\mathrm{O}$.Yu. The magnetic field of power transmission lines and the methods of its mitigation to a safe level. Technical Electrodynamics, 2013, no.2, pp. 3-9. (Rus).

2. Active Magnetic Shielding (Field Cancellation). Available at: http://www.emfservices.com/afcs.html (accessed 10 September 2012).

3. Ter Brake H.J.M., Huonker R., Rogalla H. New results in active noise compensation for magnetically shielded rooms. Measurement Science and Technology, 1993, Vol. 4, Issue 12, pp. 1370-1375. doi: 10.1088/0957-0233/4/12/010.

4. Celozzi S., Garzia F. Active shielding for power-frequency magnetic field reduction using genetic algorithms optimization. IEE Proceedings - Science, Measurement and Technology, 2004, Vol.151, no.1, pp. 2-7. doi: 10.1049/ip-smt:20040002.

5. Shenkman A., Sonkin N., Kamensky V. Active protection from electromagnetic field hazards of a high voltage power line. HAIT Journal of Science and Engineering. Series B: Applied Sciences and Engineering, Vol. 2, Issues 1-2, pp. 254-265.

6. Beltran H., Fuster V., García M. Magnetic field reduction screening system for a magnetic field source used in industrial applications. 9 Congreso Hispano Luso de Ingeniería Eléctrica (9 CHLIE), Marbella (Málaga, Spain), 2005, pp. 84-99.

7. Electrical installation regulations. 5th ed. The Ministry of Energy and Coal Mining of Ukraine, 2014. 277 p. (Ukr).

8. Rozov V.Yu., Grinchenko V.S., Pelevin D.Ye., Chunikhin K.V. Simulation of electromagnetic field in residential buildings located near overhead lines. Technical electrodynamics, 2016, no.3, pp. 6-8. (Rus).

9. Kuznetsov B.I., Nikitina T.B., Voloshko A.V., Bovdyj I.V., Vinichenko E.V., Kobilyanskiy B.B.. Synthesis of an active shielding system of the magnetic field of power lines based on multiobjective optimization. Electrical engineering \& electromechanics, 2016, no.6, pp. 26-30. (Rus). doi: 10.20998/2074-272X.2016.6.05.
10. Ren Z., Pham M.-T., Koh C.S. Robust Global Optimization of Electromagnetic Devices With Uncertain Design Parameters: Comparison of the Worst Case Optimization Methods and Multiobjective Optimization Approach Using Gradient Index. IEEE Transactions on Magnetics, 2013, vol.49, no.2, pp. 851859. doi: 10.1109/tmag.2012.2212713.

11. Ummels M. Stochastic Multiplayer Games: Theory and Algorithms. Amsterdam University Press, Amsterdam, 2010. 174 p. doi: $\mathbf{1 0 . 5 1 1 7 / 9 7 8 9 0 8 5 5 5 0 4 0 2}$.

12. Rozov V.Yu., Reutskyi S.Yu. Pyliugina O.Yu. The method of calculation of the magnetic field of three-phase power lines. Technical electrodynamics, 2014, no.5, pp. 11-13. (Rus).

13. Panchenko V.V., Maslii A.S., Pomazan D.P., Buriakovskyi S.G. Determination of pulsation factors of the system of suppression of interfering harmonics of a semiconductor converter. Electrical engineering \& electromechanics, 2018, no.4, pp. 24-28. (Rus). doi: 10.20998/2074-272X.2018.4.04.

14. Buriakovskyi S., Maslii An., Maslii Ar. Determining parameters of electric drive of a sleeper-type turnout based on electromagnet and linear inductor electric motor. EasternEuropean Journal of Enterprise Technologies, 2016, vol.4, no.1(82), pp. 32-41. (Rus). doi: 10.15587/1729-4061.2016.75860. 15. Zagirnyak M., Chornyi O., Nykyforov V., Sakun O., Panchenko K. Experimental research of electromechanical and biological systems compatibility. Przeglad Elektrotechniczny, 2016, no.1, pp. 128-131. doi: 10.15199/48.2016.01.31.

16. Buriakovskyi S.G., Maslii A.S., Panchenko V.V., Pomazan D.P., Denis I.V. The research of the operation modes of the diesel locomotive CHME3 on the imitation model. Electrical engineering \& electromechanics, 2018, no.2, pp. 59-62. (Ukr). doi: 10.20998/2074-272X.2018.2.10.

17. Shoham Y., Leyton-Brown K. Multiagent Systems: Algorithmic, Game-Theoretic, and Logical Foundations. Cambridge University Press, 2009. 504 p.

18. Kuznetsov B.I., Nikitina T.B., Voloshko A.V., Bovdyj I.V., Vinichenko E.V., Kobilyanskiy B.B. Experimental research of magnetic field sensors spatial arrangement influence on efficiency of closed loop of active screening system of magnetic field of power line. Electrical engineering \& electromechanics, 2017, no.1, pp. 16-20. (Rus). doi: 10.20998/2074-272X.2017.1.03.

Received 10.05.2018

B.I. Kuznetsov ${ }^{1}$, Doctor of Technical Science, Professor,

T.B. Nikitina ${ }^{2}$, Doctor of Technical Science, Professor,

V.V. Kolomiets ${ }^{2}$, Candidate of Technical Science,

I.V. Bovdui ${ }^{1}$, Candidate of Technical Science,

A.V. Voloshko ${ }^{1}$, Candidate of Technical Science,

E.V. Vinichenko ${ }^{1}$, Candidate of Technical Science,

${ }^{1}$ State Institution «Institute of Technical Problems

of Magnetism of the NAS of Ukraine»,

19, Industrialna Str., Kharkiv, 61106, Ukraine, phone +380 505766900 ,

e-mail: kuznetsov.boris.i@gmail.com

${ }^{2}$ Kharkov National Automobile and Highway University, 25, Yaroslava Mudroho Str., Kharkov, 61002, Ukraine, e-mail: tatjana55555@gmail.com 